\title{
An Integrated Approach Based on Network Pharmacology Combined with Experimental Verification Reveals AMPK/PI3K/Akt Signaling is an Important Way for the Anti-Type 2 Diabetic Activity of Silkworm Excrement
}

This article was published in the following Dove Press journal: Diabetes, Metabolic Syndrome and Obesity: Targets and Therapy

\author{
Huxinyue Duan* \\ Qing Zhang* \\ Jia Liu \\ Ruolan Li \\ Wei Peng \\ Chunjie Wu iD \\ School of Pharmacy, Chengdu University \\ of Traditional Chinese Medicine, \\ Chengdu, 6I II37, People's Republic of \\ China \\ *These authors contributed equally to \\ this work
}

Correspondence: Wei Peng; Chunjie Wu School of Pharmacy, Chengdu University of Traditional Chinese Medicine, No.

I I66, Liutai Avenue, Chengdu, 6IIII37,

People's Republic of China

Tel +86-028-6I80I00I

Email pengwei@cdutcm.edu.cn;

wucjcdtcm@163.com
Objective: This study was aimed to investigate the potential active components, targets and mechanisms of silkworm excrement (SE) in the treatment of type 2 diabetes mellitus $\left(\mathrm{T}_{2} \mathrm{D}\right)$ based on THE network pharmacology combined with experimental verification.

Methods: Firstly, the inhibitory effects of SE on $\alpha$-glucosidase were measured in vitro. Then, the potential active components and potential targets of SE and the targets of $\mathrm{T}_{2} \mathrm{D}$ were collected and screened using bioinformatics databases. Then, the $\mathrm{R}$ language, Cytoscape, Perl software were used to screen and visualize important components, targets, biological processes and signaling pathways. Finally, the predicted results by network pharmacology were verified via glucose absorption assay, oil red $\mathrm{O}$ staining assay and Western blot assay. Results: Our results showed SE effectively inhibited the activities of $\alpha$-glucosidase. The results of network pharmacology suggested there were 33 potential active ingredients and 42 potential targets in SE. The molecular pathways of SE against $\mathrm{T}_{2} \mathrm{D}$ were further predicted, including response to insulin-like growth factor receptor binding, protein serine/threonine kinase activity, and MAP kinase activity. KEGG pathway analyses predicted potential targets were involved in multiple signaling pathways, such as insulin signaling pathway, insulin resistance pathway and AMPK signaling pathway. In IR HepG2 cells, SE treatments increased glucose consumption and decreased lipogenesis. The insulin resistance (IR)related AMPK/PI3K/AKT signaling was further studied and the results showed SE could significantly up-regulate the phosphorylation levels of AMPK, PI3K, and Akt proteins in IRHepG2 cells.

Conclusion: Our results suggested AMPK/PI3K/Akt signaling is an important way for the anti-type 2 diabetic activity of silkworm excrement by using an integrated approach based on network pharmacology combined with experimental verification.

Keywords: $\alpha$-glucosidase, insulin resistance, network pharmacology, silkworm excrement, type 2 diabetes

\section{Introduction}

Diabetes mellitus (DM) is a complex metabolic/endocrine disease characterized by hyperglycemia. According to the pathogenesis, it is generally divided into two categories, type 1 diabetes $\left(T_{1} D\right)$ and type 2 diabetes $\left(T_{2} D\right)$. Among them, $T_{2} D$ caused by relative insufficiency in insulin or insulin resistance (IR) accounted for more than 
$90 \%{ }^{1}$ In recent years, the incidence rate of diabetes has increased rapidly, and it was estimated by the International Diabetes Federation that there would be 592 million diabetic patients in $2035 .^{2}$ In addition, diabetes could lead to a variety of complications, involving several tissues or organs, such as kidney, retina, nerve, cardiovascular, etc., which are the main causes of disability or death caused by diabetes. $^{3-5}$ However, patients with diabetes need to take hypoglycemic drugs or insulin injection for a long time, which causes serious economic burden. Therefore, it is necessary to find more anti-diabetes drugs with definite efficacy, fewer side effects and lower price.

Silkworm excrement, a traditional Chinese herbal medicine, is the dry feces of silkworm larvae of Bombyx mori L. As early as the 16th century, the use of SE to treat diabetes was recorded in ComPendium of Materia, a famous work of Chinese medicine, by Li Shizhen. ${ }^{6}$ Later, there were accumulating prescriptions containing SE used for diabetes, which were recorded by ancient Chinese doctors in their works. ${ }^{7-9}$ Currently, modern pharmacological studies have suggested that SE and its active components, especially alkaloids, have a strong ability to inhibit the activity of $\alpha$-glucosidase. ${ }^{10}$ The results of experiments in vivo showed that $\mathrm{SE}$ could improve the abnormal metabolism of glucose and lipid in diabetic mice, so it may be used for the prevention and treatment of diabetes and its complications. ${ }^{11}$ In addition, it has the advantages of obvious curative effects, low cost and few side effects. ${ }^{15}$ In this study, we verified the inhibitory effect of SE on $\alpha$ glucosidase, and then explored the active components, potential targets and mechanisms of anti-diabetes ability of $\mathrm{SE}$ on the basis of network pharmacology.

\section{Materials and Methods}

\section{Materials and Reagents}

Phosphate buffer (PBS, 0.1 mM, pH 6.8), dimethyl sulfoxide (DMSO), formaldehyde and sodium carbonate $\left(\mathrm{Na}_{2} \mathrm{CO}_{3}\right)$ were purchased from Chengdu Kelong Chemical Reagent Factory (Chengdu, China); $\alpha$-glucosidase and 4-nitrophenyl-
beta-D-glucopyranoside (PNPG) were purchased from Rhawn Chemical Reagent Company (Shanghai, China); fetal bovine serum (FBS) was purchased from HyClone Inc (Utah, USA); the Oil Red O kit and glucose assay kit were purchased from Nanjing Jiancheng Bioengineering Institute (Nanjing, China); the Cell Counting Kit-8 Cell (CCK-8) proliferation-toxicity test kit was purchased from Boster Biological Technology Company (Wuhan, China); human insulin was purchased from Sigma-Aldrich (St. Louis, MO, USA); high-glucose DMEM was purchased from GIBCO (New York, USA), radioimmunoprecipitation assay (RIPA) lysate buffer, bicinchoninic acid (BCA) protein quantitative kit, and SDS-polyacrylamide gel electrophoresis (SDS-PAGE) preparation kit were purchased from Multi Sciences (Hangzhou, China); primary antibodies for AMPK, phosphorylation- (p-) AMPK, PI3K, p-PI3K, Akt, and p-Akt were obtained from the ImmunoWay Biotechnology Co. (Suzhou, China), horseradish peroxidase- (HPR-) conjugated secondary antibody were purchased from the Beyotime Institute of Biotechnology (Haimen, China).

\section{Preparation of Lyophilized Powder of SE Extract (SEE)}

All 18 batches of silkworm excrement (YP001, YP002, YP003, YP004, YP005, YP006, YP007, YP008, YP009, YP010, YP011, YP012, YP013, YP014, YP015, YP016, YP017, YP018, Figure 1) were purchased from Bozhou medicinal materials market (Bozhou, China), and identified by Prof. Chun-jie Wu of Chengdu University of traditional Chinese medicine (CS20181108). Total 50 $\mathrm{g}$ SE was added to distilled water in the ratio of 1:7, then decocted twice for $1 \mathrm{~h}$ every time. Combining the decoction and filtering with gauze. Then the filtrate was collected to centrifuge at the speed of $12,000 \mathrm{rpm}$ for 10 minutes. After being centrifuged, the supernatant was taken and lyophilized to obtain lyophilized powder of SEE.

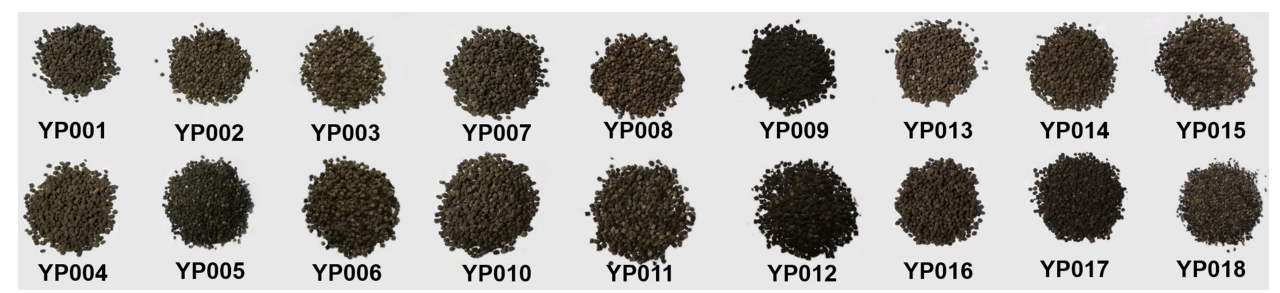

Figure I Pictures of 18 batches of silkworm excrement. 


\section{Measurement of Inhibitory Effects of SEE on $\alpha$-Glucosidase Activity}

The inhibitory effect of SEE on $\alpha$-glucosidase activity was determined according to the method reported by Barik et al with some modifications. ${ }^{12}$ Briefly, the lyophilized powder of SEE was dissolved in appropriate amount of DMSO $(10 \%$ of the total volume of sample solutions), and then diluted to different concentrations $(16.25,32.5,65,130$ and $260 \mu \mathrm{g} /$ $\mathrm{mL}$ ) by adding PBS (0.1 M; pH 7.0). A mixture system containing $20 \mu \mathrm{L}$ of PBS, $40 \mu \mathrm{L}$ PNPG $(3 \mathrm{mM})$ and $20 \mu \mathrm{L}$ SEE with different concentrations in a 96-well plate were prepared and pre-incubated for $15 \mathrm{~min}$ at $37^{\circ} \mathrm{C}$; then $20 \mu \mathrm{L}$ of $\alpha$-glucosidase $(0.5 \mathrm{U} / \mathrm{mL})$ was added to the mixture system, and incubated at $37^{\circ} \mathrm{C}$ for $20 \mathrm{~min}$. Finally, the reaction was stopped by adding $150 \mu \mathrm{L}$ of sodium carbonate $(0.2 \mathrm{M})$. Then, the absorbance of each well was measured at $405 \mathrm{~nm}$ by a microplate reader. In this experiment, the $\alpha$-glucosidase and PNPG solutions were prepared in PBS. SEE was replaced by the equal volume of PBS as negative control, and $\alpha$-glycosidase was replaced by equal volume PBS as sample blank group. Those without sample and enzyme were regarded as blank group. The inhibition rate of each concentration was calculated according to the following formula: Inhibition rate $(\%)=\left[1-\left(\Delta \mathrm{A}_{\text {sample }}-\Delta \mathrm{A}_{\text {sample blank }}\right) /\right.$ $\left.\left(\Delta \mathrm{A}_{\text {negative control }}-\Delta \mathrm{A}_{\text {blank }}\right)\right] \times 100 \%$, and the $\mathrm{IC}_{50}$ values were calculated using the online software of "IC50 Calculator” (https://www.aatbio.com/tools/ic50-calculator).

\section{Active Ingredients Screening}

The components of silkworm excrement (SE) were collected from PubMed (https://pubmed.ncbi.nlm.nih.gov/), ScienceDirect (https://www.sciencedirect.com/), Web of Science (https://apps.webofknowledge.com/), and CNKI (https://www.cnki.net/) with "Cansha" and "silkworm excrement" as searching key words. In addition, active components were screened through the therapeutic effects of these components on diabetes which were reported in related articles. Then, download structures of these potential ingredients as a MOL file format from PubChem (https://pubchem.ncbi.nlm.nih.gov/).

\section{Potential Targets Library Establishment}

The MOL files of potential compounds were uploaded to SwissTargetPrediction (http://www.swisstargetpredic tion.ch/), an online database, to obtain potential targets of these small molecules. The targets of disease were collected from the Gene Expression Omnibus (GEO) database (https://www.ncbi.nlm.nih.gov/geo/) with "type 2 diabetes" as the keyword. In addition, screening criteria of target genes are $\mathrm{P}$ value $<0.05$ and $\mid \log 2$ (fold change) $\mid>1$. Then, the predicted targets of active components from SE and diabetes-related genes were overlapped to construct the targets library.

\section{Protein-Protein Interaction (PPI) Network Construction}

To explain the interaction among target proteins, the target proteins were entered into the online STRING database (https://string-db.org/) to construct the protein-protein interaction (PPI) network with the species limitation of Homo sapiens, and the PPI with a score greater than 0.7 was retained. The obtained analysis results were downloaded in CSV format and imported into Cytoscape $\left(\right.$ ver.3.7.1) ${ }^{13}$ to visualize the PPI network. Furthermore, the hub targets in PPI were analyzed and selected by using the CytohHubba plug-in and R language software.

\section{GO Functional Annotation and KEGG Pathway Analysis}

Gene Ontology (GO) and Kyoto Encyclopedia of Genes and Genomes (KEGG) pathway enrichment analysis were carried out to analyze the biological term classification and pathway enrichment of the screened target proteins using $\mathrm{R}$ language software. The related functions or pathways were selected under the criteria of $\mathrm{P}<0.05$, and only the top 20 were shown in the results.

\section{Drug-Molecular-Target-Disease Network Construction}

The drug-molecular-target-disease network (DMTD) was constructed through Cytoscape. In the network diagram, nodes represent drugs, components, diseases and targets, and edges represent the interaction between them. Clearly, this network diagram can show the interrelationships between each node.

\section{Cell Culture and Induction of an Insulin Resistant Model}

HepG2 cells, kindly donated by Prof. Qinwan Huang of Chengdu University of traditional Chinese medicine, were cultured in high-glucose DMEM containing 10\% FBS and $1 \%$ antibiotic solution $(100 \mathrm{U} / \mathrm{mL}$ penicillin and 
$100 \mu \mathrm{g} / \mathrm{mL}$ streptomycin) at $37^{\circ} \mathrm{C}$ in a $5 \% \mathrm{CO}_{2}$ humidified atmosphere. The establishment of insulin resistance model was determined according to the method reported by Chen et al, ${ }^{14}$ with some modifications. Briefly, HepG2 cells were seeded in 96-well plates at $1 \times 10^{5}$ cells/well $(100 \mu \mathrm{L} /$ well $)$ for $24 \mathrm{~h}$ until the density reached $80 \%$. Then, cells were cultured in serum-free medium for starvation for $24 \mathrm{~h}$. The serum-free medium was then replaced with high-glucose DMEM with $5 \times 10^{-7} \mathrm{M}$ recombinant human insulin for 48 $\mathrm{h}$ to induce IR.

\section{Cell Viability Assay}

The HepG2 cells $\left(1 \times 10^{5}\right.$ cells/well $)$ were seeded in a 96well plate and cultured for $24 \mathrm{~h}$ to allow cell adherence. Cells were then treated with SEE at different concentrations $(0.1,0.2,0.4,0.8,1.6$ and $3.2 \mathrm{mg} / \mathrm{mL}$, diluted in DMEM) for another $24 \mathrm{~h}$. Then, $10 \mu \mathrm{L} \mathrm{CCK}-8$ and $90 \mu \mathrm{L}$ fresh medium were added to each well, following by removing of the SEE-containing medium, and cells were incubated under conditions at $37^{\circ} \mathrm{C}$ and $5 \% \mathrm{CO}_{2}$ for $1 \mathrm{~h}$. The absorbance was measured at $490 \mathrm{~nm}$ with a microplate reader. The complete growth medium was used as the blank control group.

\section{Glucose Uptake Assay}

As described above, HepG2 cells were cultured in serumfree medium for starvation for $24 \mathrm{~h}$, then cultured in highglucose DMEM with $5 \times 10^{-7} \mathrm{M}$ recombinant human insulin for $48 \mathrm{~h}$ to induce IR. ${ }^{9}$ Subsequently, the IR-HepG2 cells were treated with different concentrations of SEE $(0.4,0.8$ and $1.6 \mathrm{mg} / \mathrm{mL})$. Finally, glucose uptake assays were detected using a glucose assay kit (glucose oxidase method) to evaluate anti-diabetic effects.

\section{Oil Red O Staining Assay}

To detect the intracellular lipogenesis of HepG2 cells, the cells were stained with oil red $\mathrm{O}$ (ORO) staining according to the standard instructions of the commercial kit. Briefly, the cells were fixed with $4 \%$ formaldehyde for 15 minutes and then washed twice with PBS. Then, cells were stained with oil red $\mathrm{O}$ for $15 \mathrm{~min}$, then washed with distilled water at $37^{\circ} \mathrm{C}$ for $5-20 \mathrm{~s}$, following by staining with hematoxylin (HE), and finally photographed by microscopy.

\section{Western Blot Analysis}

HepG2 cells were harvested and total proteins were extracted by RIPA lysis buffer for $30 \mathrm{~min}$, and then centrifuged at $12,000 \mathrm{rpm}$ for $15 \mathrm{~min}$. The supernatant was harvested and used to quantify the protein concentrations using the BCA protein assay kit. After protein samples were mixed with sample loading buffer $(4: 1, \mathrm{v} / \mathrm{v})$, they were boiled in water bath for $5 \mathrm{~min}$. Next, the target proteins were separated using SDS-PAGE and then transferred to the polyvinylidene fluoride (PVDF) membranes. The PVDF membranes were blocked by 5\% skimmed milk. Then, the membranes were incubated with the primary antibodies of AMPK, p-AMPK, PI3K, p-PI3K, AKT and p-AKT (dilution 1:1000) overnight at $4^{\circ} \mathrm{C}$. Subsequently, the membranes were incubated with HRPconjugated secondary antibody at room temperature for 1 h. Finally, the target protein bands were visualized by chemiluminescence detection with BeyoECL Star kits, and $\beta$-actin was used as the internal reference. The protein bands were photographed and saved to analysis using the ImageJ software (version: 1.51, National Institutes of Health, MD, USA).

\section{Statistical Analysis}

The data obtained from the experiments were shown as mean \pm SD, and all the data were analyzed by SPSS 19.0 software. The differences between and within-group were analyzed by using one-way ANOVA. $\mathrm{P}<0.05$ indicated that the difference was considered significant.

\section{Results}

\section{SEE Significantly Inhibits $\alpha$-Glucosidase Activity}

As shown in Figure $2 \mathrm{~A}-\mathrm{C}$, all the 18 batches of $\mathrm{SE}$ showed inhibitory effect on $\alpha$ - glucosidase activity with concentration-dependent manner, and the inhibitory rate of high concentration of SEE was higher than $80 \%$. Then, the $\mathrm{IC}_{50}$ for 18 batches of silkworm excrement extracts were calculated according to the concentration corresponsive curves (Figure 2D).

\section{Active Anti-Diabetic Compound of SEE}

According to articles searching, 36 compounds were collected as potential active components in SE. Based on literature mining, it has been demonstrated that 33 compounds of that 36 have effects on anti-diabetes, and their information is shown in Table 1 .

\section{Diabetic Targets of Active Compounds}

After deleting duplicated genes, 437 potential targets of SE were obtained from the SwissTargetPrediction online 

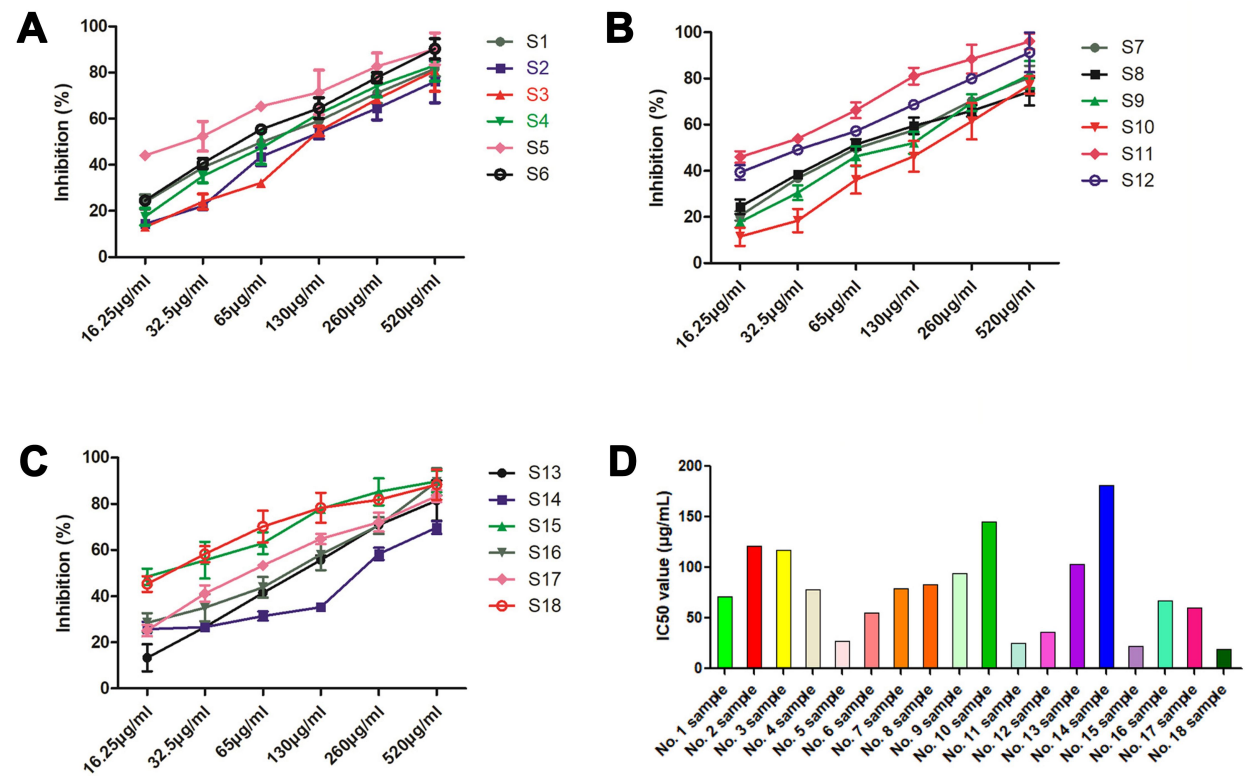

Figure 2 Effects of the SE on $\alpha$-glucosidase activity. (A-C) Inhibitory effects of the 18 batches of SE against $\alpha$-glucosidase activity; (D): The IC 50 value of the I8 batches of SE. Abbreviations: $S E$, silkworm excrement; $T_{2} D$, type 2 diabetes.

database. And diabetes-associated genes were collected from the GEO database. Transcriptomic data GSE20966, GSE25724 and GSE38642 with corresponding platform GPL1352, GPL96 and GPL6244 were used to screening differentially expressed genes (DEG) between diabetes mellitus (DM) and non-diabetic samples. Volcano maps were drawn to show the distribution of genes, and the red dots represented up-regulated genes and the green dots represented down-regulated genes (Figure 3A). There were 75 up-regulated genes and 362 down regulated genes. Finally, combining the target sets of active components and disease, the Venn diagram shows 42 potential targets of active compounds were associated with diabetes (Figure 3B).

\section{PPI Analysis}

As shown in Figure 4, the node represents the target proteins, while the edge represents the interaction between the two proteins. Total 33 proteins and 43 edges were obtained, and the most important 20 targets were screened out, as shown in Figure 4, including insulin, Paired Box 6, Tyrosine-protein kinase ABL1, Glycoprotein VI Platelet and Purinergic receptor P2Y12, suggesting that these proteins may be the main targets for SE to play an antidiabetic role.

\section{Target Biological Function Analysis}

The results of GO functional enrichment analysis were showed, and $\mathrm{P}<0.05$ was used as the screening condition
(Figure 5). The results were divided into three categories: biological process (BP), cellular component (CC) and molecular function (MF). Biological process mainly included regulation of protein secretion, regulation of peptide secretion, activation of protein kinase activity and positive regulation of protein secretion. Cellular component included glutamatergic synapse, plasma membrane receptor complex and postsynaptic cytosol. Molecular function mainly included insulin-like growth factor receptor binding, protein serine/threonine kinase activity, scaffold protein binding, integrin binding and MAP kinase activity. Similarly, the $\mathrm{R}$ language software was used to perform KEGG analysis, and the top 20 pathways are shown in Figure 6, including Insulin signaling pathway, Insulin resistance (IR), HIF-1 signaling pathway, AMPK signaling pathway, etc., which were relevant to insulin signaling pathways.

\section{Drug-Molecular-Target-Disease Network}

As is shown in Figure 7, the DMTD network diagram containing 77 node and 448 edges, including 33 molecules (the targets of the two molecules were not overlapped with disease's targets) and 42 targets proteins. In the picture, the disease and targets are in the left half, and the drug and active ingredients are in the right half. The interaction between the targets of active components of SE and DM is shown in the network diagram, and the color of nodes represents the degree of interaction. The deeper color represented a greater interaction degree. 
Table I Potential Active Compounds in SE

\begin{tabular}{|c|c|c|c|c|c|}
\hline ID & Molecule Name & Chemical Structure & $\begin{array}{l}\text { Molecular } \\
\text { Formula }\end{array}$ & $\begin{array}{l}\text { MW } \\
(\mathrm{g} / \mathrm{mol})\end{array}$ & Refs \\
\hline $\mathrm{Cl}$ & 7,2'-dihydroxy-8-prenyl-4'-methoxyflavane & & $\mathrm{C}_{21} \mathrm{H}_{24} \mathrm{O}_{4}$ & 340.4 & 16 \\
\hline $\mathrm{C} 2$ & Euchrenone-A7 & & $\mathrm{C}_{20} \mathrm{H}_{20} \mathrm{O}_{5}$ & 340.4 & 16 \\
\hline C3 & $\begin{array}{l}\text { 7,2'-dihydroxy-8-hydroxyethyl-4'-methoxyflavane-2'-O- } \beta \text { - } \\
\text { D-glucopyranoside }\end{array}$ & & $\mathrm{C}_{24} \mathrm{H}_{30} \mathrm{O}_{10}$ & 478.5 & 16 \\
\hline $\mathrm{C} 4$ & $\begin{array}{l}\text { 7,2'-dihydroxy-8-prenyl-4'-methoxy-2'-O- } \beta \text { - } \\
\text { D-glucopyranosylflavane }\end{array}$ & & $\mathrm{C}_{27} \mathrm{H}_{34} \mathrm{O}_{9}$ & 502.6 & 16 \\
\hline C6 & $(6 S, 9 R)-3-o x o-\alpha$-ionol- $\beta$-D-glucopyranoside & & $\mathrm{C}_{19} \mathrm{H}_{30} \mathrm{O}_{7}$ & 370.2 & 15 \\
\hline $\mathrm{C7}$ & Blumenol C glucoside & & $\mathrm{C}_{19} \mathrm{H}_{32} \mathrm{O}_{7}$ & 372.5 & 15 \\
\hline $\mathrm{C} 8$ & Byzantionoside B & & $\mathrm{C}_{19} \mathrm{H}_{32} \mathrm{O}_{7}$ & 372.5 & 15 \\
\hline
\end{tabular}

(Continued) 
Table I (Continued).

\begin{tabular}{|c|c|c|c|c|c|}
\hline ID & Molecule Name & Chemical Structure & $\begin{array}{l}\text { Molecular } \\
\text { Formula }\end{array}$ & $\begin{array}{l}\text { MW } \\
\text { (g/mol) }\end{array}$ & Refs \\
\hline $\mathrm{ClO}$ & (6R,7E,9R)-9-hydroxy-4,7-megastigmadien-3-one & & $\mathrm{C}_{13} \mathrm{H}_{21} \mathrm{O}_{2}$ & 209.1 & 17 \\
\hline $\mathrm{Cll}$ & $(6 R, 9 R)-9-h y d r o x y-4-m e g a s t i g m e n-3-o n e$ & & $\mathrm{C}_{13} \mathrm{H}_{20} \mathrm{O}_{2}$ & 208.1 & 17 \\
\hline $\mathrm{Cl} 3$ & Alangionoside $\mathrm{L}$ & & $\mathrm{C}_{19} \mathrm{H}_{32} \mathrm{O}_{7}$ & 372.5 & 16 \\
\hline $\mathrm{Cl} 4$ & I-Deoxynojirimycin & $\mathrm{CH}_{2} \mathrm{OH}$ & $\mathrm{C} 6 \mathrm{HI} 3 \mathrm{NO} 4$ & 163.2 & 10 \\
\hline $\mathrm{Cl} 5$ & $\mathrm{~N}$-methyl-I-deoxynojirimycin & $\mathrm{CH}_{2} \mathrm{OH}$ & $\mathrm{C} 7 \mathrm{HI} 5 \mathrm{NO} 4$ & 177.2 & 10 \\
\hline $\mathrm{Cl} 6$ & Fagomine & $\mathrm{CH}_{2} \mathrm{OH}$ & $\mathrm{C} 6 \mathrm{HI} 3 \mathrm{NO} 3$ & 147.2 & 10 \\
\hline $\mathrm{Cl} 7$ & 3-Epi-fagomine & $\mathrm{CH}_{2} \mathrm{OH}$ & $\mathrm{C} 6 \mathrm{HI} 3 \mathrm{NO} 3$ & 147.2 & 17 \\
\hline
\end{tabular}

(Continued) 
Table I (Continued).

\begin{tabular}{|c|c|c|c|c|c|}
\hline ID & Molecule Name & Chemical Structure & $\begin{array}{l}\text { Molecular } \\
\text { Formula }\end{array}$ & $\begin{array}{l}\text { MW } \\
(\mathrm{g} / \mathrm{mol})\end{array}$ & Refs \\
\hline $\mathrm{Cl} 8$ & 2-O- $\alpha$-Glucopyranosy-I-4-deoxynojirimycin & & $\mathrm{Cl} 2 \mathrm{H} 23 \mathrm{O} 9 \mathrm{~N}$ & 325.9 & 15 \\
\hline $\mathrm{Cl} 9$ & 2-O- $\alpha$-Glucopyranosyl-I-deoxynojirimycin & $\mathrm{CH}_{2} \mathrm{OH}$ & $\mathrm{CI} 2 \mathrm{HI} 8 \mathrm{O} 9 \mathrm{~N}$ & 320.1 & 10 \\
\hline $\mathrm{C} 20$ & I,4-Dideoxy-I,4-Imino-D-Arabinitol & & $\mathrm{C} 5 \mathrm{HIINO} 3$ & 133.2 & 10 \\
\hline C2I & I,4-Dideoxy-I,4-Imino-D-Ribitol & & $\mathrm{C} 5 \mathrm{HIINO}$ & 133.2 & 10 \\
\hline $\mathrm{C} 22$ & $\begin{array}{l}\text { I,4-dideoxy-I,4-imino-(2-O- } \beta \text {-D-glucopyranosyl)- } \\
\text { D-arabinitol }\end{array}$ & & $\mathrm{CIIH} 2 \mathrm{IO} 8 \mathrm{~N}$ & 295.1 & 10 \\
\hline $\mathrm{C} 23$ & $\begin{array}{l}\text { I,4-dideoxy-I,4-imino-(2-O- } \alpha \text {-D-glucopyranosyl)- } \\
\text { D-arabinitol }\end{array}$ & & $\mathrm{C} 7 \mathrm{HI} 3 \mathrm{O} 4 \mathrm{~N} 2$ & 189.1 & 10 \\
\hline C24 & $\begin{array}{l}(I R, 2 S, 3 R, 4 S, 5 R)-8 \text {-azabicyclo[3.2.I]octane-1,2,3,4-tetrol, } \\
\text { calystegin B2 }\end{array}$ & & $\mathrm{C} 7 \mathrm{HI} 3 \mathrm{O} 4 \mathrm{~N}$ & 175.1 & 15 \\
\hline
\end{tabular}

(Continued) 
Table I (Continued).

\begin{tabular}{|c|c|c|c|c|c|}
\hline ID & Molecule Name & Chemical Structure & $\begin{array}{l}\text { Molecular } \\
\text { Formula }\end{array}$ & $\begin{array}{l}\text { MW } \\
(\mathrm{g} / \mathrm{mol})\end{array}$ & Refs \\
\hline $\mathrm{C} 25$ & Calystegin $\mathrm{Cl}$ & & $\mathrm{C} 7 \mathrm{HI} 3 \mathrm{O} 5 \mathrm{~N}$ & 191.1 & 15 \\
\hline $\mathrm{C} 26$ & $2 \alpha, 3 \beta$-Dihydroxynortropane & & $\mathrm{C} 7 \mathrm{HI} 3 \mathrm{O} 2 \mathrm{~N}$ & 143.1 & 15 \\
\hline $\mathrm{C} 27$ & $2 \beta, 3 \beta$-Dihydroxynortropane & & $\mathrm{C} 7 \mathrm{HI} 3 \mathrm{O} 2 \mathrm{~N}$ & 143.1 & 15 \\
\hline $\mathrm{C} 28$ & $2 \alpha, 3 \beta-6$ exo-Trihydroxy-Nortropane & & $\mathrm{C} 7 \mathrm{HI} 3 \mathrm{O} 3 \mathrm{~N}$ & 159.1 & 15 \\
\hline C29 & $2 \alpha, 3 \beta, 4 \alpha$-Trihydroxy-Nortropane & & $\mathrm{C} 7 \mathrm{HI} 3 \mathrm{O} 3 \mathrm{~N}$ & 159.1 & 15 \\
\hline C30 & 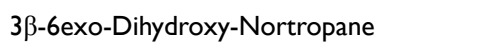 & & $\mathrm{C} 7 \mathrm{HI} 3 \mathrm{O} 6 \mathrm{~N}$ & 207.1 & 15 \\
\hline C31 & $3 \beta, 6 \beta$-Dihydroxy-Nortropane & & $\mathrm{C} 7 \mathrm{HI} 3 \mathrm{O} 3 \mathrm{~N}$ & 159.1 & 16 \\
\hline C32 & 4-O- $\alpha$-D-Galactopyranosyl-Calystegin B2 & & $\mathrm{Cl} 4 \mathrm{H} 25 \mathrm{O} 9 \mathrm{~N}$ & 351.1 & 15 \\
\hline
\end{tabular}

(Continued) 
Table I (Continued).

\begin{tabular}{|c|c|c|c|c|c|}
\hline ID & Molecule Name & Chemical Structure & $\begin{array}{l}\text { Molecular } \\
\text { Formula }\end{array}$ & $\begin{array}{l}\text { MW } \\
\text { (g/mol) }\end{array}$ & Refs \\
\hline $\mathrm{C} 33$ & $\begin{array}{l}(2 \mathrm{R}, 3 \mathrm{R}, 4 \mathrm{R}) \text {-2-hydroxymethyl-3,4-dihydroxypyrrolidine- } \\
\mathrm{N} \text {-glyoxylamide }\end{array}$ & & $\mathrm{C} 7 \mathrm{HI} 2 \mathrm{O} 5 \mathrm{~N} 2$ & 204.1 & 10 \\
\hline C34 & $(2 R, 3 R, 4 R)-2-[(S)-1,2-d i h y d r o x y e t h y \mid] p i p e r i d i n e-3,4-d i o l$ & & $\mathrm{C} 7 \mathrm{HI} 5 \mathrm{O} 4 \mathrm{~N}$ & 177.1 & 10 \\
\hline C35 & N,N-Bis (2-chloroethyl) ethylenedia & & $\mathrm{C} 6 \mathrm{H} 14 \mathrm{~N} 2 \mathrm{Cl} 2$ & 185.0 & 10 \\
\hline C36 & meso-Erythritol & & $\mathrm{C} 4 \mathrm{HI} 0 \mathrm{O} 4$ & 122.1 & 10 \\
\hline
\end{tabular}

\section{Effect of SEE on Glucose Consumption in IR HepG2 Cells}

As shown in Figure 8A, after treating with SEE at the concentration of $3.2 \mathrm{mg} / \mathrm{mL}$, the viability of HepG2 cells was significantly reduced, and no significant cytotoxicity was observed at concentrations below $3.2 \mathrm{mg}$ / $\mathrm{mL}$ of SEE compared with normal cells, suggesting that it was safe for HepG2 cells with SEE treatment lower than $3.2 \mathrm{mg} / \mathrm{mL}$.

As shown in Figure 8B, SEE at the concentration of $1.6 \mathrm{mg} / \mathrm{mL}$ significantly increased the glucose consumption in IR HepG2 cells, compared to the model group $(\mathrm{P}<$ $0.001)$. Thus, $\operatorname{SEE}(1.6,0.8$ and $0.4 \mathrm{mg} / \mathrm{mL}$ ) may prevent the decrease of glucose consumption stimulated by high insulin in IR HepG2 cells $(\mathrm{P}<0.001)$.

\section{SEE Reduces Lipogenesis in IR HepG2 Cells}

As shown in Figure 9, effects of SEE on intracellular lipogenesis were determined in the IR-HepG2 cells. The oil red $\mathrm{O}(\mathrm{ORO})$ staining revealed a severe steatosis in high insulin-induced IR HepG2 cells, compared to the untreated control cells. Lipid accumulation in the cells treated with $\mathrm{SE}(0.4,0.8$, and $1.6 \mathrm{mg} / \mathrm{mL})$ was significantly reduced with a concentration-dependent manner.

\section{SEE Up-Regulates AMPK/PI3K/Akt Signaling in IR-HepG2 Cells}

As shown in Figure 10, the expressions of PI3K, p-PI3K, AKT, p-AKT, AMPK and p-AMPK in HepG2 cells were down-regulated after stimulation with high-glucose DMEM and recombinant human insulin, compared to normal cells. However, SEE treatment $(1.6 \mathrm{mg} / \mathrm{mL})$ upregulated the expressions of PI3K, p-PI3K, Akt, p-AKT, AMPK and p-AMPK, compared with the model group, suggesting that SEE treatment could activate the AMPK/ PI3K/Akt signaling in IR HepG2 cells.

\section{Discussion}

Diabetes is a complex metabolic disease characterized by hyperglycemia, and often accompanied by various complications. $^{18}$ Due to the characteristics of multicomponent, multi-target and few side effects, traditional 
A

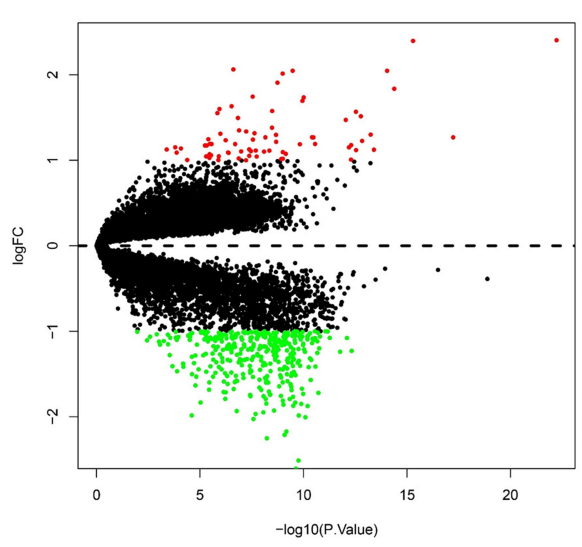

B

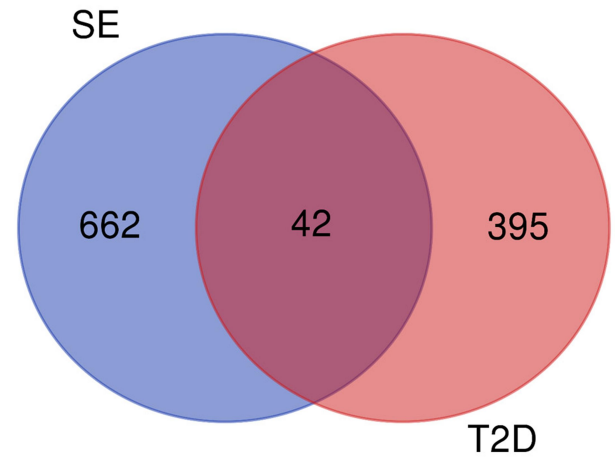

Figure 3 (A) Volcano map of the differential genes. Threshold was set to be $\log _{2}|F C|>I$ and $P<0.05$; (B) Venn diagram of $T_{2} D$-associated targets and predicted targets of active components.

A

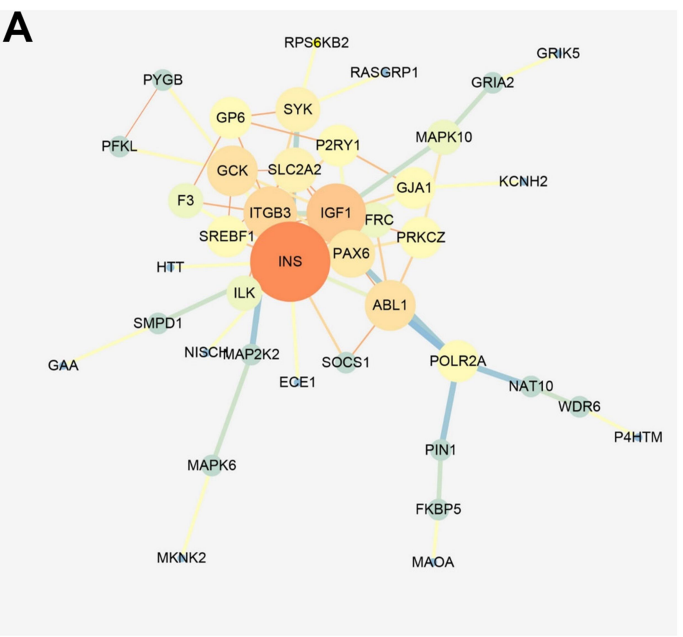

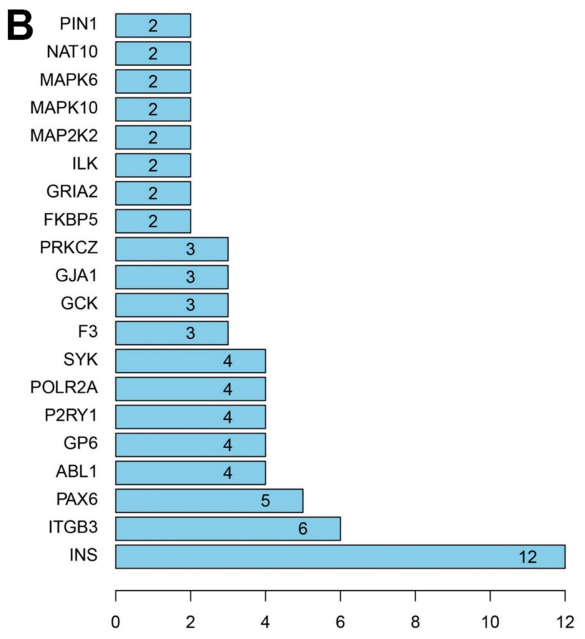

Figure 4 Protein-protein interaction network (PPI) of target proteins. (A) The key targets of the intersections of $\mathrm{T}_{2} \mathrm{D}$ and SE in PPI (Cytoscape); (B) The key targets of the intersections of $T_{2} D$ and SE in PPI.

Chinese medicines (TCMs) have become a research focuses in recent years. ${ }^{19,20}$ Accumulating studies have shown that silkworm excrement, a TCM with a long history of application, has the pharmacological effects of hypoglycemic, antioxidant, anti-inflammatory, anti-tumor and so on, and could be used as a potential anti-diabetic drug. ${ }^{11,20-22}$ In 2007, Liu et al reported that the extract of silkworm excrement could inhibit the activity of $\alpha$ glucosidase and improve the abnormal glucose and lipid metabolism in diabetic mice. ${ }^{11}$ In addition, Lin et al reported in 2016 that sugar-mimic alkaloids extracted from silkworm excrement had obvious $\alpha$-glucosidase inhibitory activity, and could be used for the prevention of hyperglycemia. ${ }^{10}$ However, there are few studies on the active components and molecular mechanisms of silkworm excrement, which limits its application. In this study, the potential active compounds and drug targets of SE and the possible mechanism were screened out via using network pharmacology.

First of all, the freeze-dried powder of SE was prepared and used to verify its hypoglycemic activity in vitro. The results showed that SE significantly inhibited the production of glucosidase. It is suggested that SE has hypoglycemic effect and is worthy of further study. Then, we explored the potential active ingredients, targets and mechanism of SE in hypoglycemic effect based on network pharmacology. The results indicated that there were 33 possible active components of SE, including 2-O- $\alpha$-glucopyranosyl-4-deoxynojirimycin, N,N-bis (2-chloroethyl) ethylenedia, (2R, 3R, 4R)-2-[(S)-1, 2-dihydroxyethyl] piperidine-3, 4-diol, 1, 4-dideoxy-1, 4-imino-(2-O- $\alpha$ D-glucopyranosyl)-D-arabinitol, N-methyl-1-deoxynojirimycin, alangionoside L, 7,2'-dihydroxy-8-prenyl-4'- 

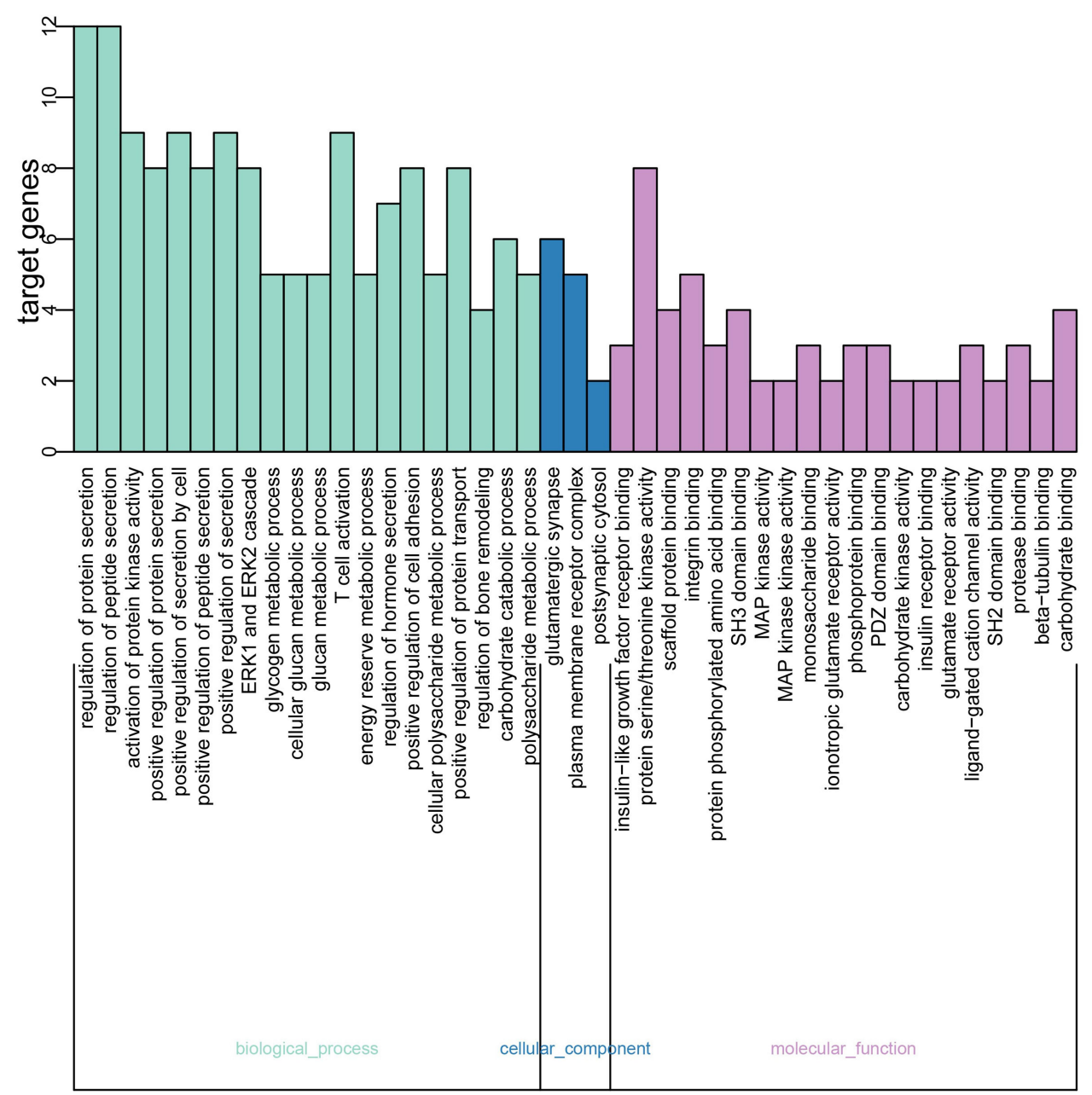

Figure 5 GO functions enrichment.

A

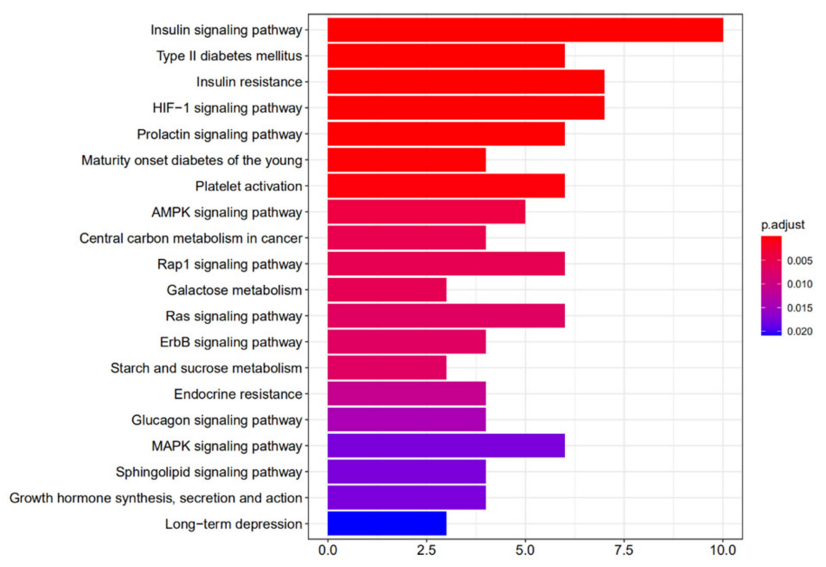

B

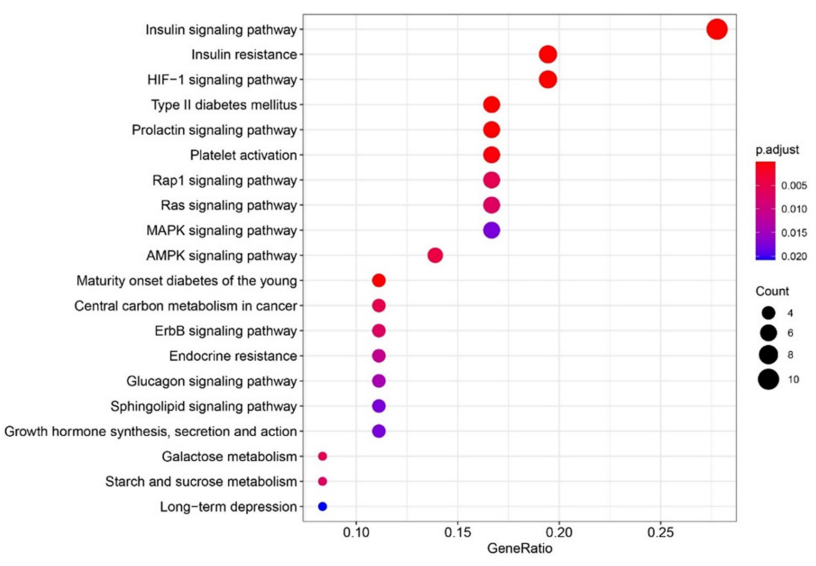

Figure 6 KEGG pathways analysis of overlapping target genes (top 20). (A) Bar chart of KEGG; (B) Bubble chart of KEGG.

methoxyflavane. Then, the top 20 potential targets were obtained by functional enrichment analysis and were involved in pathways including insulin signaling pathway, insulin resistance pathway, AMPK signaling pathway and HIF-1 signaling pathway. It has been reported that PI3K/Akt pathway plays an important role in insulin signaling pathway, ${ }^{23}$ and 


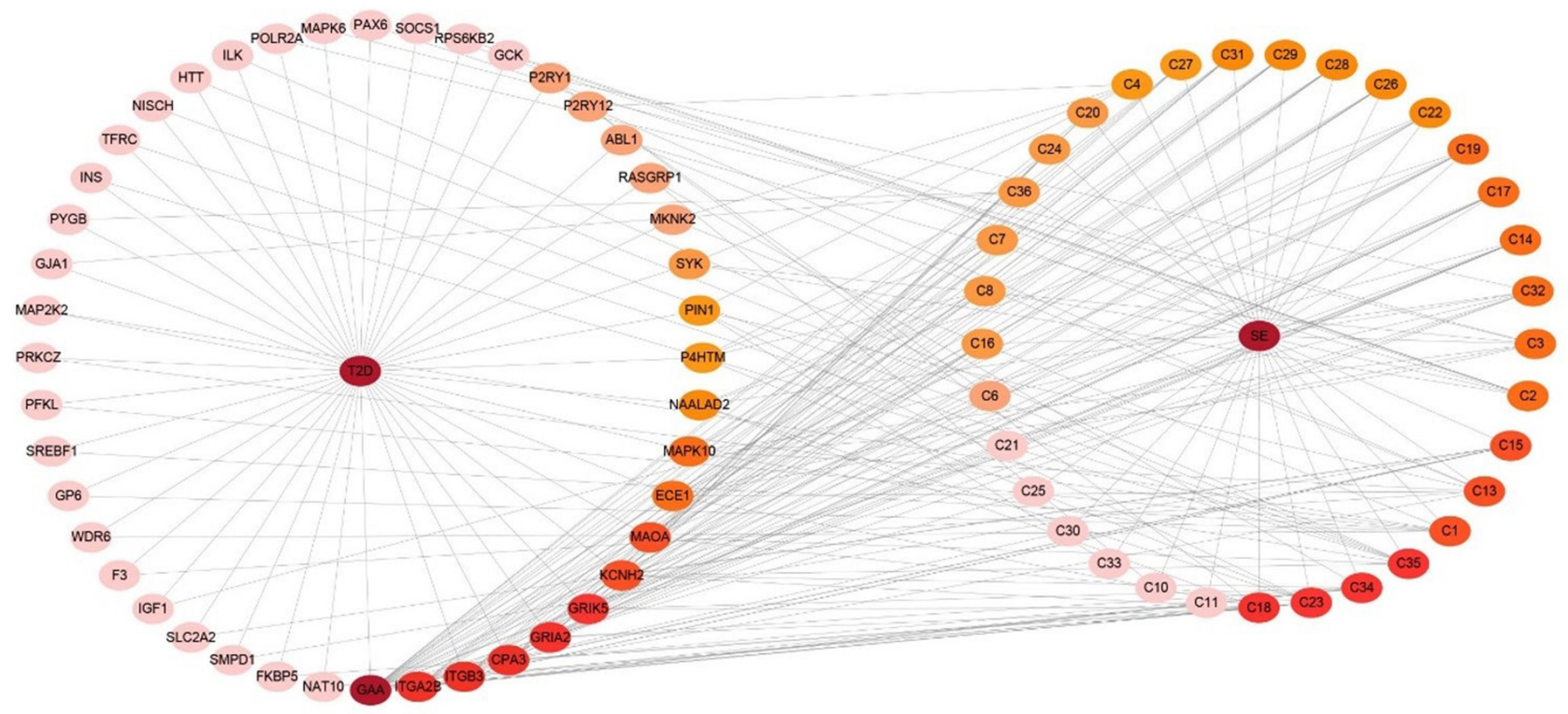

Figure 7 Drug-molecular-target-disease network diagram. The color of nodes represents the value of degree, and the deeper color represented a greater interaction degree.

A

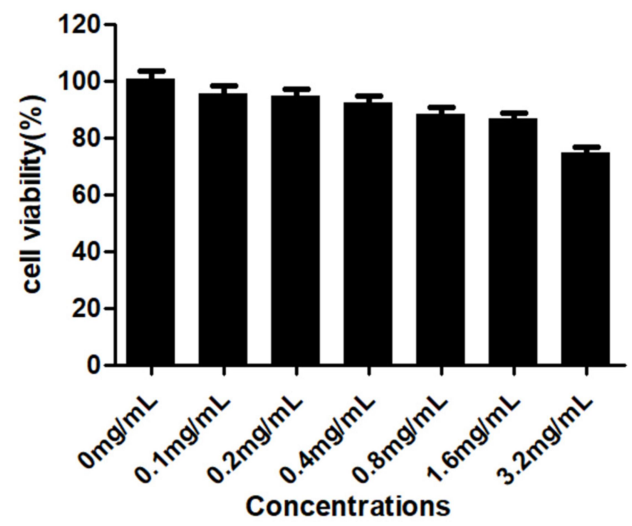

B

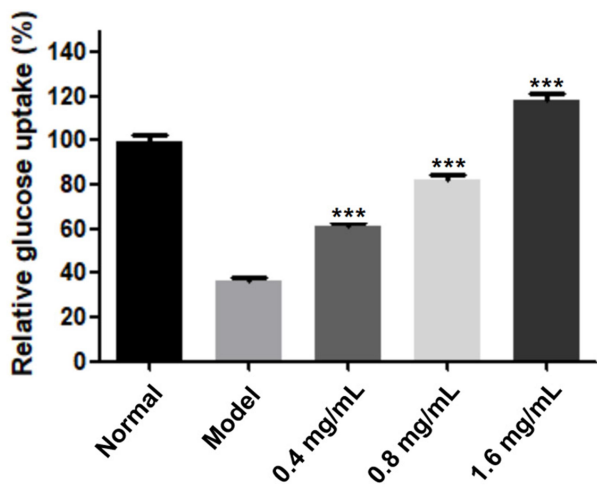

Figure 8 Effects of SEE on cell viability and glucose uptake in high insulin-induced IR-HepG2 cells. (A) Cell viability of HepG2 cells cultured in different concentrations of SEE from 0 to $3.2 \mu \mathrm{g} / \mathrm{mL}$ for $24 \mathrm{~h}$. (B) Glucose consumption of IR HepG2 cells incubated with or without SEE $(0.4,0.8,1.6 \mu \mathrm{g} / \mathrm{mL})$ for $24 \mathrm{~h}$. ${ }^{* * *} \mathrm{P}<0.00 \mathrm{I}$ vs the model group.

AMPK was closely linked to insulin resistance (IR), ${ }^{24,25}$ so these two signaling pathways were selected to verify the antidiabetic mechanisms of SE. Insulin, a peptide hormone released by pancreatic beta cells, is part of a family of peptides which includes insulin-like growth factors (IGF) I and $\mathrm{II}^{26}$ It has the ability to regulate the blood glucose levels, which is of great significance to maintain the glucose balance in vivo. ${ }^{27}$ It has been reported that the abnormal glucose absorption may be related to the modification of insulin signaling, which could lead to insulin resistance (IR). ${ }^{28}$ Insulin resistances refer to the decrease of insulin sensitivity in insulin target tissues, such as liver, muscle and adipocytes, resulting in the decrease of glucose utilization, which is one of the important pathogenesis of $\mathrm{T}_{2} \mathrm{D} .{ }^{29}$ Liver is one of the most important organs to maintain glucose homeostasis. However, insulin resistance disordered the balance between gluconeogenesis and glycogen synthesis in liver, and then led to high blood glucose. ${ }^{22}$ PI3K/AKT pathway plays an important role in insulin signaling pathway, especially in insulin resistance of liver. ${ }^{30,31} 5^{\prime}$-adenosine monophosphate (AMP)-activated protein kinase (AMPK) is a serine/threonine kinase, which plays an important role in regulating energy metabolism. ${ }^{32}$ In liver, AMPK maintained 


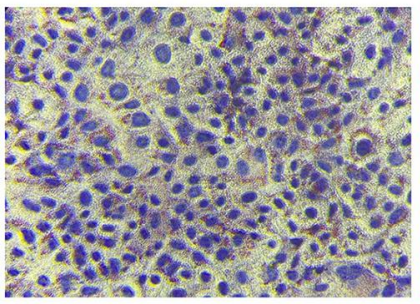

Normal

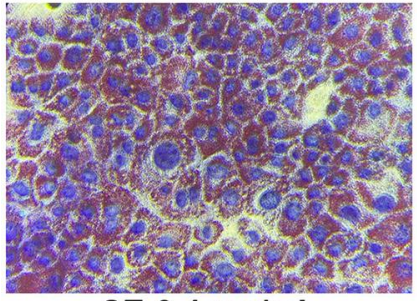

SE-0.4 mg/mL

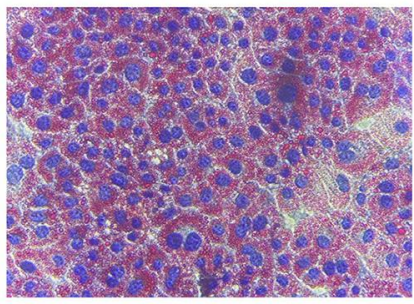

Model

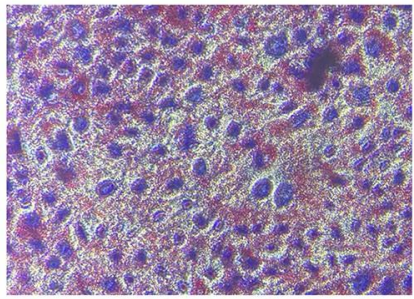

$\mathrm{SE}-0.8 \mathrm{mg} / \mathrm{mL}$

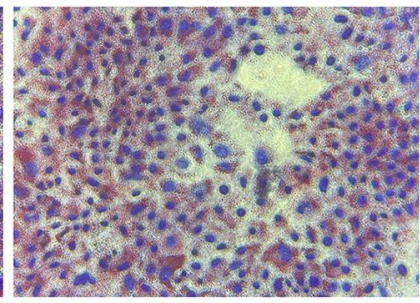

$\mathrm{SE}-1.6 \mathrm{mg} / \mathrm{mL}$

Figure 9 Effect of SEE on lipogenesis in IR-HepG2 cells. The red represents the lipid droplets, and blue represents the nucleus. Abbreviation: SE, silkworm excrement.
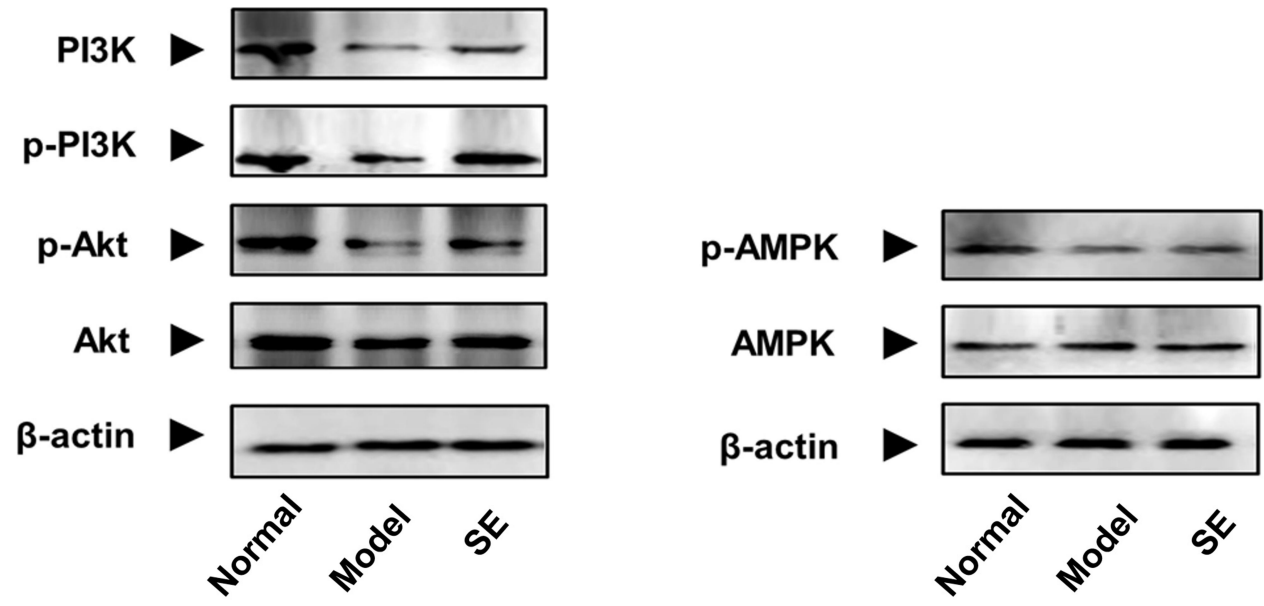

Figure 10 Effect of SEE on protein expressions of AMPK/PI3K/Akt in IR - HepG2 cells.

Abbreviations: PI3K, phosphoinositide 3-kinase; P-PI3K, phosphorylation PI3K; Akt, protein kinase B; p-Akt, phosphorylation Akt; AMPK, 5'-adenosine monophosphateactivated protein kinase; p-AMPK, phosphorylation AMPK; SE, silkworm excrement.

glucose homeostasis by promoting hepatic glycogen synthesis and inhibiting gluconeogenesis. ${ }^{33,34}$ It has been reported that stimulation of AMPK could improve blood glucose level in animal models with diabetes. ${ }^{35}$ Besides, activating AMPK could improve insulin sensitivity by inhibiting adipogenesis, which was related to the phosphorylation of IRS-1/2, ER stress/ROS and free fatty acids. ${ }^{25}$ In addition, activation of AMPK regulated hepatic PI3K/Akt signaling pathway and then improved insulin resistance. ${ }^{36,37}$ In this study, we induced IR-HepG2 cells, and found that SE could increase glucose absorption and reduce lipogenesis to improve insulin resistance in IR-HepG2 cells, from the results of glucose absorption assay and oil red $\mathrm{O}$ staining assay. Furthermore, the expression of PI3K, Akt, and AMPK in IR-HepG2 cells was determined by Western blot. The results showed that SE could significantly up-regulate the prototype and phosphorylation of PI3K, Akt, and AMPK in IR-HepG2 cells, suggesting that SE may improve insulin resistance in IR-HepG2 cells via regulating AMPK/PI3K/Akt signaling.

\section{Conclusion}

In conclusion, our results suggested AMPK/PI3K/Akt signaling is an important way for the anti-type 2 diabetic activity of silkworm excrement by using an integrated approach 
based on network pharmacology combined with experimental verification. Our present findings would be beneficial to the future development of the silkworm excrement as an effective drug for treating type 2 diabetes in clinical.

\section{Abbreviations}

AMPK, mitogen-activated protein kinase; DEG, differentially expressed genes; DM, diabetes mellitus; DMSO, dimethyl sulfoxide; DMTD, drug-molecular-targetdisease network; GCK, glucokinase; GEO, Gene Expression Omnibus; GIPR, GIP receptor; GO, Gene Ontology; GPR40, G protein-coupled receptor; IGF, insulin-like growth factors; IR, insulin resistance; KEGG, Kyoto Encyclopedia of Genes and Genomes; ORO, oil red O; PBS, Phosphate buffer; PNPG, 4-nitrophenyl-beta -D-glucopyranoside; PPI, Protein-protein interaction; SE, silkworm excrement; SEE, SE extract; T1D, type 1 diabetes mellit; T2D, type 2 diabetes mellitus; TCM, traditional Chinese medicine.

\section{Availability of Materials and Data}

The data sets used and/or analyzed during the current study are available from the corresponding author upon reasonable request.

\section{Ethics Statements}

The use of the HepG2 cell lines was approved by the ethics committee of the Chengdu University of Traditional Chinese Medicine (No. 202,006-1). In addition, the HepG2 cells were authenticated by STR profile (See the supplementary file).

\section{Acknowledgment}

We would like to acknowledge Chengdu University of Traditional Chinese Medicine for providing the necessary facilities in this study.

\section{Funding}

This research was supported by the Project of Administration of Traditional Chinese Medicine of Sichuan Province of China (No. 2020HJZX001), Xinglin Scholar Discipline Promotion Talent Program of Chengdu University of Traditional Chinese Medicine (No. BSH2018006), and Project of Open Research Fund of Chengdu University of Traditional Chinese Medicine Key Laboratory of Systematic Research of Distinctive Chinese Medicine Resources in Southwest China (No. 2020XSGG021).

\section{Disclosure}

The authors declare that they have no competing interests in this work.

\section{References}

1. Fang PH, Shi MY, Zhu Y, et al. Type 2 diabetes mellitus as a disorder of galanin resistance. Exp Gerontol. 2016;73:72-77. doi:10.1016/j. exger.2015.11.007

2. Guariguata L, Whiting DR, Hambleton I, et al. Global estimates of diabetes prevalence for 2013 and projections for 2035. Diabetes Res Clin Pract. 2014;103(2):137-149. doi:10.1016/j.diabres.2013.11.002

3. Zheng Y, Ley SH, Hu FB. Global aetiology and epidemiology of type 2 diabetes mellitus and its complications. Nat Rev Endocrinol. 2017;14(2):88-98. doi:10.1038/nrendo.2017.151

4. Henning RJ. Type-2 diabetes mellitus and cardiovascular disease. Future Cardiol. 2018;14(6):491-509. doi:10.2217/fca-2018-0045

5. Zamfirov K, Philippe J. Musculoskeletal complications in diabetes mellitus. Rev Med Suisse. 2017;13(560):917.

6. Li SZ. ComPendium of Materia Medica. Peking: People's Medical Publishing House; 1982.

7. Tao HJ. Mingyi Bielu. Peking: People's Medical Publishing House; 1982.

8. Chen CQ. Supplement to Materia Medica. Shang ZJ, ed. Wuhu: Wannan Medicine College; 1983.

9. Zhao QG. Bencao Qiuyuan. Peking: China Press of Traditional Chinese Medicine; 2016.

10. Lin JF, Wang YH, He XJ. Sugar-mimic alkaloids from faeces bombycis and their pronounced $\alpha$-glucosidase inhibitory activities. Am Chem Sci J. 2016;14(1):1-9. doi:10.9734/ACSJ/2016/25834

11. Liu Q, Qiao FX, Ye F, et al. Anti-diabetic activity of the extraction from Cansha (Bombyx mori L.) as a novel alpha-glucosidase inhibitor. Chinese J New Drugs. 2007;19:1589-1592.

12. Barik SK, Russell WR, Moar KM, et al. The anthocyanins in black currants regulate postprandial hyperglycaemia primarily by inhibiting $\alpha$-glucosidase while other phenolics modulate salivary $\alpha$-amylase, glucose uptake and sugar transporters. $J$ Nutr Biochem. 2020;78:108325. doi:10.1016/j.jnutbio.2019.108325

13. Shannon P, Markiel A, Ozier O, et al. Cytoscape: a software environment for integrated models of biomolecular interaction networks. Genome Res. 2003;13(11):2498-2504. doi:10.1101/gr.1239303

14. Chen L, Teng H, Cao H. Chlorogenic acid and caffeic acid from Sonchus oleraceus Linn synergistically attenuate insulin resistance and modulate glucose uptake in HepG2 cells. Food Chem Toxicol. 2019;127:182-187. doi:10.1016/j.fct.2019.03.038

15. Zheng TY, Dai XX, Su SL, et al. Analysis and evaluation of multiple types of chemical constituents in silkworm excrement from different habitats and at different various instars. Chinese J Pharmaceutical Analysis. 2019;39(04):624-637.

16. Park JH, Lee DY, Yun P, et al. Flavonoids from silkworm droppings and their promotional activities on heme oxygenase-1. J Asian Nat Prod Res. 2011;13(4):377-382. doi:10.1080/10286020.2011.555331

17. Park JH, Lee DG, Yeon SW, et al. Isolation of megastigmane sesquiterpenes from the silkworm (Bombyx mori L.) droppings and their promotion activity on HO-1 and SIRT1. Arch Pharm Res. 2011;34 (4):533-542. doi:10.1007/s12272-011-0403-x

18. DeFronzo RA. Pathogenesis of type 2 diabetes mellitus. Med Clin North Am. 2004;88(4):787-835. doi:10.1016/j.mcna.2004.04.013

19. Lee WY, Park JH, Kim BS, et al. Chlorophyll derivatives (CpD) extracted from silk worm excreta are specifically cytotoxic to tumor cells in vitro. Yonsei Med J. 1990;31(3):225. doi:10.3349/ymj.1990.31.3.225

20. Zhang Q, Liu J, Li R, et al. A network pharmacology approach to investigate the anticancer mechanism and potential active ingredients of Rheum palmatum L. against lung cancer via induction of apoptosis. Front Pharmacol. 2020;11:528308. doi:10.3389/fphar.20 20.528308 
21. Feng Q, Liu L, Luo F, et al. Scavenging effect on active oxygen of metal chlorophylls from silkworm excrement. Chinese Traditional Herbal Drugs. 2004;07:36-39.

22. Shi WJ, Yang YF, Zhu S, et al. Studies on anti-inflammatory effect and analgesic effect of silkworm shit. Asia-Pacific Traditional Med. 2013;09:44-46.

23. Whiteman EL, Cho H, Birnbaum MJ. Role of Akt/protein kinase B in metabolism. Trends Endocrinol Metab. 2020;13(10):444-451. doi:10.1016/s1043-2760(02)00662-8

24. Lochhead PA, Salt IP, Walker KS, et al. 5-aminoimidazole-4-carboxamide riboside mimics the effects of insulin on the expression of the 2 key gluconeogenic genes PEPCK and glucose-6-phosphatise. Diabetes. 2000;49(6):896-903. doi:10.2337/diabetes.49.6.896

25. Zhou G, Myers R, Li Y, et al. Role of AMP-activated protein kinase in mechanism of metformin action. J Clin Invest. 2001;108 (8):1167-1174. doi:10.1172/JCI13505

26. Jeon SM. Regulation and function of AMPK in physiology and diseases. Exp Mol Med. 2016;48(7):e245. doi:10.1038/emm.2016.81

27. Weiss M, Steiner DF, Philipson LH. Insulin biosynthesis, secretion, structure, and structure-activity relationships. In: Feingold KR, editor. Endotext. MDText.com, Inc; 2014.

28. Perry RJ, Samuel VT, Petersen KF, et al. The role of hepatic lipids in hepatic insulin resistance and type 2 diabetes. Nature. 2014;510 (7503):84-91. doi:10.1038/nature13478

29. Samuel VT, Shulman GI. The pathogenesis of insulin resistance: integrating signaling pathways and substrate flux. J Clin Invest. 2016;126(1):12. doi:10.1172/JCI77812

30. Liu TY, Shi CX, Gao R, et al. Irisin inhibits hepatic gluconeogenesis and increases glycogen synthesis via the PI3K/Akt pathway in type 2 diabetic mice and hepatocytes. Clin sci. 2015;129(10):839-850. doi:10.1042/CS20150009
31. Yan F, Dai G, Zheng X. Mulberry anthocyanin extract ameliorates insulin resistance by regulating $\mathrm{PI} 3 \mathrm{~K} / \mathrm{AKT}$ pathway in HepG2 cells and $\mathrm{db} / \mathrm{db}$ mice. J Nutr Biochem. 2016;36:68-80. doi:10.1016/j. jnutbio.2016.07.004

32. Yan J, Wang C, Jin Y, et al. Catalpol ameliorates hepatic insulin resistance in type 2 diabetes through acting on AMPK/NOX4/PI3K/ AKT pathway. Pharmacol Re. 2018;130:466-480. doi:10.1016/j. phrs.2017.12.026

33. Zhang BB, Zhou G, Li C. AMPK: an emerging drug target for diabetes and the metabolic syndrome. Cell Metab. 2009;9 (5):407-416. doi:10.1016/j.cmet.2009.03.012

34. Horike N, Sakoda H, Kushiyama A, et al. AMP-activated protein kinase activation increases phosphorylation of glycogen synthase kinase 3 beta and thereby reduces cAMP-responsive element transcriptional activity and phosphoenolpyruvate carboxykinase $\mathrm{C}$ gene expression in the liver. J Biol Chem. 2008;283(49):33902-33910. doi:10.1074/jbc.M802537200

35. Joshi T, Singh AK, Haratipour P, et al. Targeting AMPK signaling pathway by natural products for treatment of diabetes mellitus and its complications. J Cell Physiol. 2019;234(10):17212-17231. doi:10.10 02/jcp. 28528

36. Zheng T, Yang $\mathrm{X}$, Wu D, et al. Salidroside ameliorates insulin resistance through activation of a mitochondria-associated AMPK/ PI3K/Akt/GSK3beta pathway. Br J Pharmacol. 2015;172(13):32 84-3301. doi:10.1111/bph.13120

37. Xiao F, Huang $\mathrm{Z}$, Li $\mathrm{H}$, et al. Leucine deprivation increases hepatic insulin sensitivity via GCN2/mTOR/S6K1 and AMPK pathways. Diabetes. 2011;60(3):746-756. doi:10.2337/db10-1246

\section{Publish your work in this journal}

Diabetes, Metabolic Syndrome and Obesity: Targets and Therapy is an international, peer-reviewed open-access journal committed to the rapid publication of the latest laboratory and clinical findings in the fields of diabetes, metabolic syndrome and obesity research. Original research, review, case reports, hypothesis formation, expert opinion and commentaries are all considered for publication. The manuscript management system is completely online and includes a very quick and fair peer-review system, which is all easy to use. Visit http://www.dovepress.com/testimonials.php to read real quotes from published authors.

Submit your manuscript here: https://www.dovepress.com/diabetes-metabolic-syndrome-and-obesity-targets-and-therapy-journal 